\title{
Static Characteristics of A New Doubly Salient Permanent Magnet Motor
}

\author{
Ming Cheng, K. T. Chau, Member, IEEE, and C. C. Chan, Fellow, IEEE
}

\begin{abstract}
In this paper, magnetic field analysis of a new doubly salient permanent magnet (DSPM) motor is carried out based on finite element method (FEM). Hence, the corresponding static characteristics, including PM flux linkage, self-inductance, mutual inductance, and static torque are deduced (the interaction between the PM field and armature field are taken into account). New methods for measuring the motor inductance are also proposed. The theoretical analysis is verified by experimental results.
\end{abstract}

Index Terms-Doubly salient motors, finite element methods, inductance, inductance measurement, permanent magnet machines, static characteristics, torque.

\section{INTRODUCTION}

$\mathbf{R}$ ECENT developments of the doubly salient permanent magnet (DSPM) motor have shown that it has many advantages such as high efficiency, high power density and high energy conversion ratio [1]-[3]. Thus, more and more attention has been paid to this motor since its advent. However, the static characteristics of the motor, being the fundamentals of design, analysis and control, have received insufficient research. The PM flux linkage and the inductance in the available literatures are obtained under the assumptions that the variations of the PM flux linkage and the armature flux linkage are spatially dependent only [2]. In addition, the corresponding mutual inductance has never been mentioned.

The objective of this paper is to perform the analysis of the magnetic field distribution of the DSPM motor by using finite element method (FEM), and hence to calculate the PM flux linkage, self-inductance, mutual inductance and static torque. The iron saturation and the cross-coupling between the PM flux and armature flux will be taken into consideration. Furthermore, the inductance measurement of the DSPM motor usually suffers from a great difficulty because of the interaction of PM flux and armature flux. New methods for measuring the self- and mutual inductances are proposed for the DSPM motor. A new 6/4-pole DSPM motor with stationary PMs is designed, built and tested for exemplification. The experimental results verify the theoretical analysis.

\section{MAgnetic Field ANALYsis}

Two-dimensional (2D) finite element analysis (FEA) is used to determine the magnetic field distribution of the DSPM motor.

Manuscript received November 19, 1999. This work was supported and funded in part by the CRCG of the University of Hong Kong, the Hong Kong Research Grants Council, and NSFC under Project 59507001.

The authors are with the Department of Electrical and Electronic Engineering,

The University of Hong Kong, Hong Kong, China.

Publisher Item Identifier S 0885-8969(01)02650-X

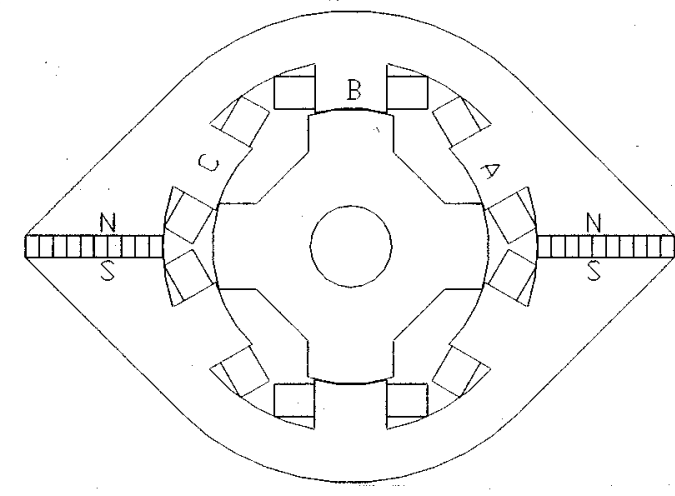

Fig. 1. Cross-section of DSPM motor.

The magnetic field prevailing in the interior of the machine can be described in terms of the vector potential. In a $2 \mathrm{D}$ rectangular coordinate, the nonlinear magnetostatic Poisson equation is given by:

$$
\left\{\begin{array}{l}
\frac{\partial}{\partial x}\left(v \frac{\partial A_{z}}{\partial x}\right)+\frac{\partial}{\partial y}\left(v \frac{\partial A_{z}}{\partial y}\right)=-\left(J_{z}-J_{c}\right) \\
S_{1}+S_{2}: A_{z}=0
\end{array}\right.
$$

where

$A_{z}$ and $J_{z} \quad$ are the $z$ components of vector potential $\vec{A}$ and current density $\vec{J}$, respectively,

$J_{c} \quad$ is the equivalent surface current density of the $\mathrm{PM}$,

$v \quad$ is the reluctivity,

$S_{1}$ and $S_{2} \quad$ denote the Dirichlet boundaries.

The equivalent variational expression to the above class of nonlinear magnetic field problems for DSPM motor can be written as:

$\left\{\begin{array}{l}W\left(A_{z}\right)=\iint_{\Omega}\left[\int_{0}^{B} v B^{\prime} d B^{\prime}-\left(J_{z}+J_{C}\right) A_{z}\right] d x d y=\min \\ \left.A_{z}\right|_{S_{1}+S_{2}}=0 .\end{array}\right.$

Fig. 1 shows the schematic configuration of the DSPM motor. Due to the semiperiodic motor configuration, the region of interests for FEA is a half of the whole motor crosssection. Fig. 2 shows the finite element mesh of this motor. Fig. 3 shows the flux distributions under no-load and load conditions with a rotor angle of $30^{\circ}$ (the rotor angle $\theta$ is defined as the angle between the central lines of stator pole and rotor slot; the rotor angle is zero as the stator pole central line aligns with the rotor slot central line). Fig. 3(a) is the PM field at no-load, Fig. 3(b) is 


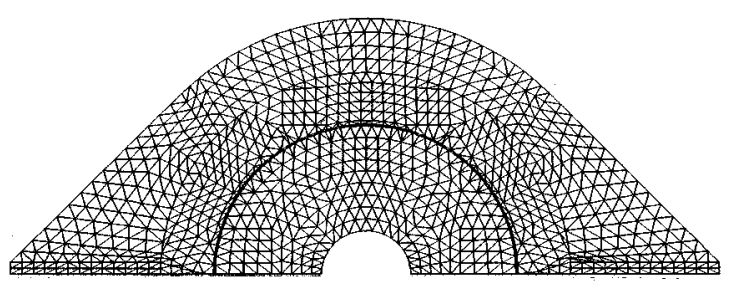

Fig. 2. Generated mesh for finite element analysis.

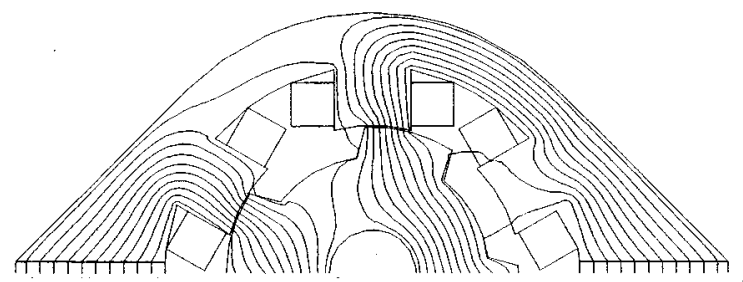

(a)

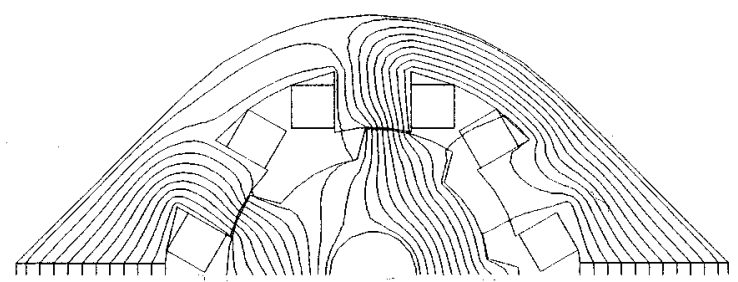

(b)

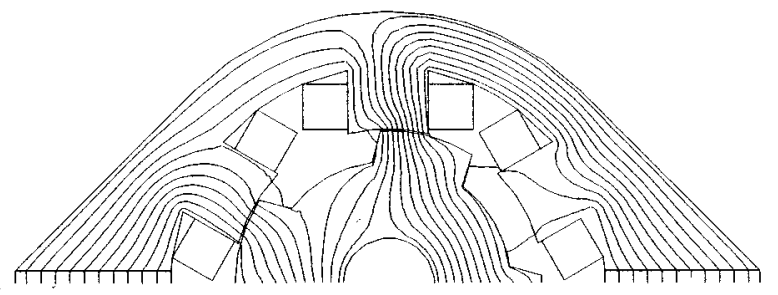

(c)

Fig. 3. Flux distributions at $\theta=30^{\circ}$ under different conditions. (a) PM. (b) $\mathrm{PM}$ and $I_{b}=2 \mathrm{~A}$. (c) PM, $I_{b} 2 \mathrm{~A}$ and $I_{c}=-2 \mathrm{~A}$.

the magnetic field produced by both PM and armature current $i_{b}$ (with strengthening action to the PM field), and Fig. 3(c) is the magnetic field produced by PM, $i_{b}$ (with strengthening action to the PM field) and $i_{b}$ (with weakening action to the PM field). The corresponding magnetic flux density distributions in the airgap are shown in Fig. 4. It can be seen that the flux in the DSPM motor is mainly contributed by PMs. The armature flux has less effect on the total flux value, but it changes the flux distribution.

\section{STATIC ChARACTERISTICS}

\section{A. PM Flux Linkage}

The PM flux linkage versus rotor angle can be obtained from the finite element analysis as shown in Fig. 5. It can be seen that the PM flux linkage varies linearly with the rotor angle in the two strokes respectively. The induced back EMF is given by:

$$
e=\frac{d \psi_{m}}{d t}=\frac{d \psi_{m}}{d \theta} \cdot \frac{2 \pi n}{60}
$$

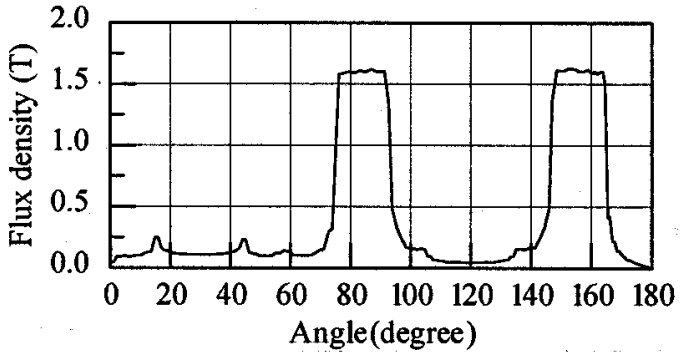

(a)

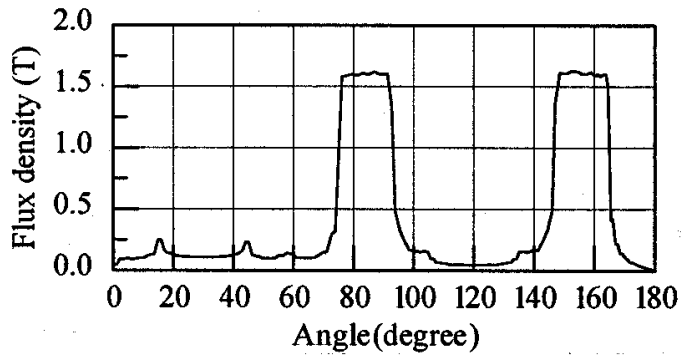

(b)

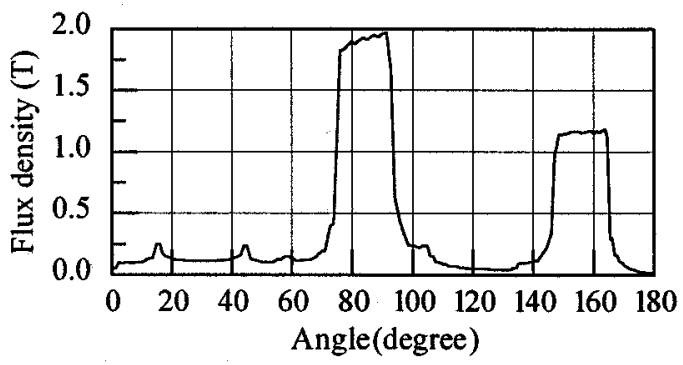

(c)

Fig. 4. Magnetic flux density in airgap at $\theta=30^{\circ}$. (a) PM. (b) $\mathrm{PM}$ and $I_{b}=$ 2 A. (c) PM, $I_{b} 2$ A and $I_{c}=-2 \mathrm{~A}$.

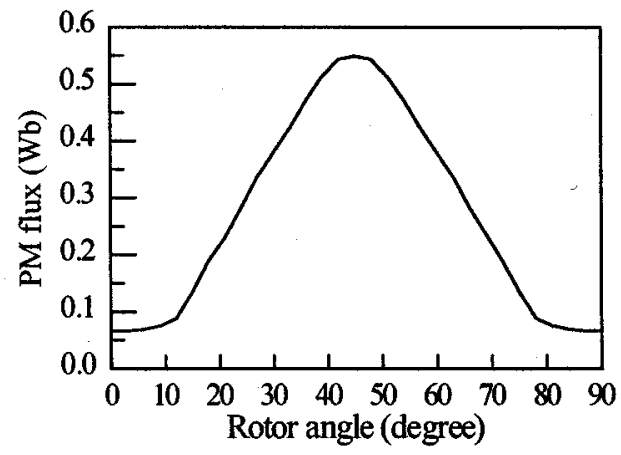

Fig. 5. PM flux linkage versus rotor angle.

where

$e \quad$ is the back EMF,

$\psi_{m}$ is the PM flux linkage,

$\theta \quad$ is the rotor angle and

$n \quad$ is the speed of the motor in rpm.

Fig. 6 shows the theoretical and measured waveforms of the back EMF of the 6/4-pole DSPM motor at the rated speed of $1500 \mathrm{rpm}$. It can be seen that the experimental result closely agrees with the theoretical one. 


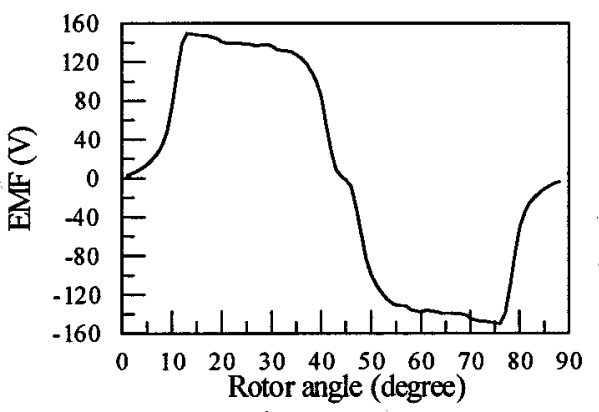

(a)

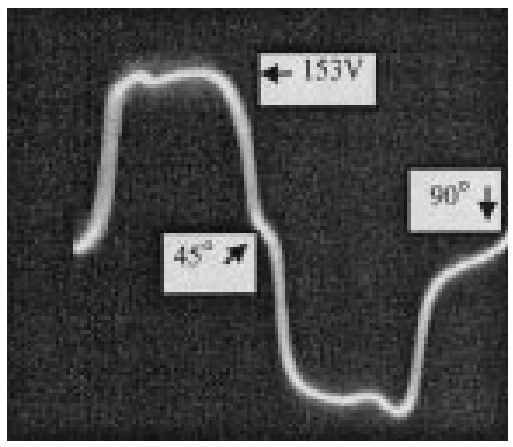

(b)

Fig. 6. Back EMF waveforms. (a) Theoretical. (b) Measured.

\section{B. Inductances}

In the calculation of inductances, the cross-coupling between the PM flux and armature flux should be taken into account. As the PM and armature current act together, the flux linkage of one phase is given by:

$$
\psi=\psi_{m}+L i
$$

where

$\psi \quad$ is the total flux linkage produced by the PM and phase current,

$L \quad$ is the inductance of one phase, and

$i \quad$ is the phase current.

Then, the inductance can be rewritten as:

$$
L=\left(\psi-\psi_{m}\right) / i
$$

Fig. 7 shows the inductance characteristics, in which "PM+2A" and "PM-2A" denote the strengthening and weakening actions of the armature field (the phase current is $2 \mathrm{~A})$ to the PM field, respectively, while " $2 \mathrm{~A}$ " denotes that the inductance is calculated at the phase current of $2 \mathrm{~A}$ without the PM field. It indicates that the self-inductances with and without the PM are very different in both the magnitude and pattern. In addition, the strengthening and weakening actions of the armature field to the PM field have significant effects on the inductance value, which should be taken into account in performance prediction and control of the DSPM motor. From Fig. 7(b), it is seen that the DSPM motor has a large mutual inductance, similar to the level of the self-inductance. Its peak value occurs at the position that the stator and rotor poles are half overlapped. Increasingly, Fig. 8 depicts the self-inductance as the function of the rotor position and current, in which positive and negative currents denote the strengthening and weakening actions to the PM field, respectively.

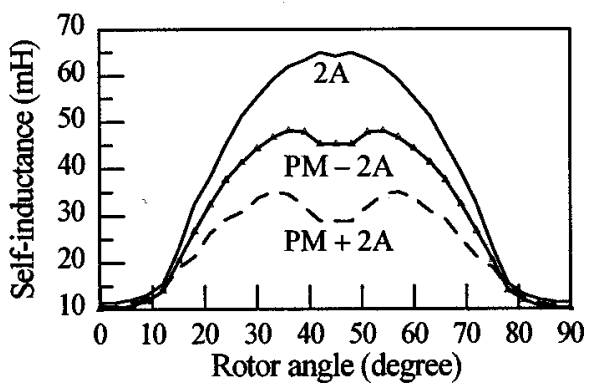

(a)

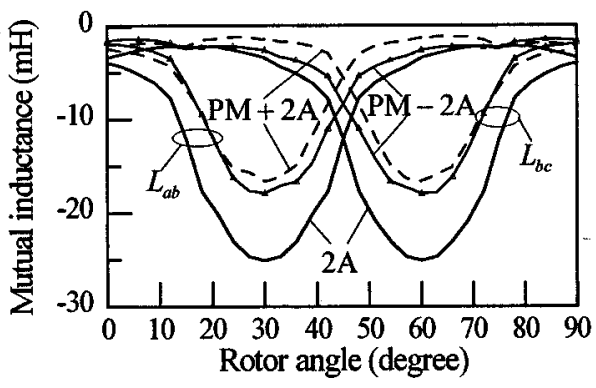

(b)

Fig. 7. Phase inductances versus rotor angle. (a) Self-inductance. (b) Mutual inductance.

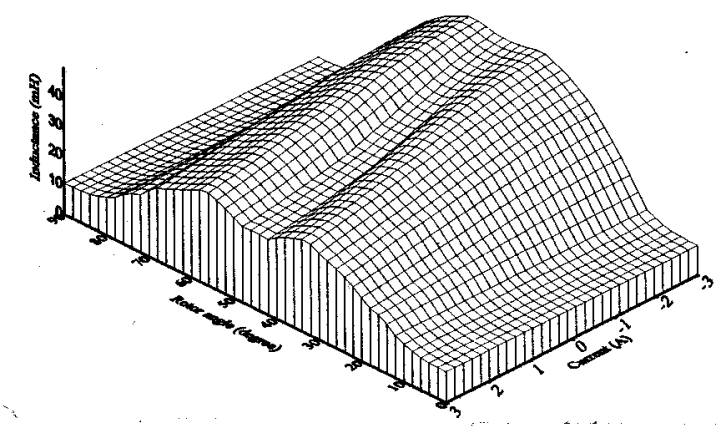

Fig. 8. Self-inductance at different rotor angles and currents.

\section{Torque}

Firstly, we consider the two-phase-on condition, say phase A and phase $\mathrm{B}$ on, the voltage equations are:

$$
\left.\begin{array}{l}
u_{a}=R i_{a}-e_{a} \approx-e_{a}=d \psi_{a} / d t \\
u_{b}=R i_{b}-e_{b} \approx-e_{b}=d \psi_{b} / d t
\end{array}\right\}
$$

where

$u_{a}$ and $u_{b}$ $e_{a}$ and $e_{b}$ $R$ $\psi_{a}$ and $\psi_{b}$

$$
\left.\begin{array}{l}
\psi_{a}=L_{a} i_{a}+L_{a b} i_{b}+\psi_{m a} \\
\psi_{b}=L_{b} i_{b}+L_{a b} i_{a}+\psi_{m b}
\end{array}\right\}
$$

where

$L_{a}$ and $L_{b}$

$L_{a b}$

$\psi_{m a}$ and $\psi_{m b}$

are the phase voltages, are the back EMFs, is the phase winding resistance, and are the flux linkages that can be expressed as:

are the self-inductances, is the mutual inductance, and are the PM flux linkages. 


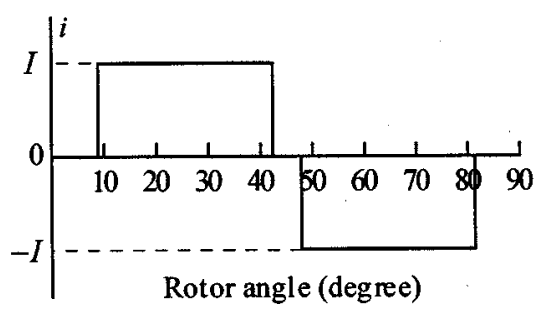

Fig. 9. Current waveform.

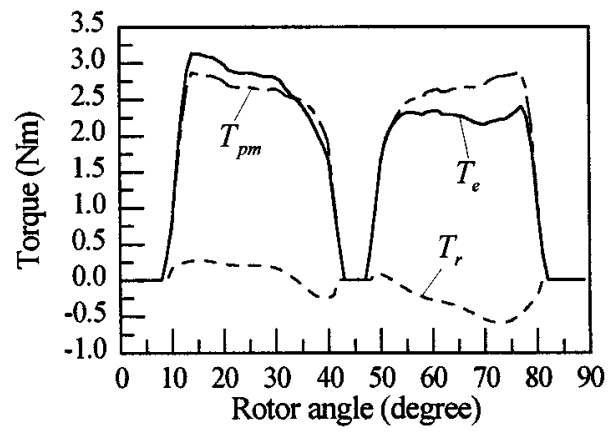

Fig. 10. Static torque and its components at $I=3 \mathrm{~A}$.

Substituting (7) into (6), it yields

$$
\left.\begin{array}{l}
-e_{a}=L_{a} \frac{d i_{a}}{d t}+i_{a} \frac{d L_{a}}{d t}+L_{a b} \frac{d i_{b}}{d t}+i_{b} \frac{d L_{a b}}{d t}+\frac{d \psi_{m a}}{d t} \\
-e_{b}=L_{b} \frac{d i_{b}}{d t}+i_{b} \frac{d L_{b}}{d t}+L_{a b} \frac{d i_{a}}{d t}+i_{a} \frac{d L_{a b}}{d t}+\frac{d \psi_{m b}}{d t}
\end{array}\right\} .
$$

Neglecting the iron and ohmic losses, the input power can be expressed as:

$$
P_{c}=u_{a} i_{a}+u_{b} i_{b} \approx-\left(e_{a} i_{a}+e_{b} i_{b}\right)=d w_{s f}+T_{c} \Omega
$$

where

$$
\begin{aligned}
w_{s f} & =L_{a} i_{a}^{2} / 2+L_{a b} i_{a} i_{b}+L_{b} i_{b}^{2} / 2 \\
T_{e} & =\frac{1}{2} i_{a}^{2} \frac{d L_{a}}{d \theta}+\frac{1}{2} i_{b}^{2} \frac{d L_{b}}{d \theta}+i_{a} i_{b} \frac{d L_{a b}}{d \theta}+i_{a} \frac{d \psi_{m a}}{d \theta}+i_{b} \frac{d \psi_{m a}}{d \theta}
\end{aligned}
$$

and $w_{s f}$ is the armature reaction field energy, $T_{c}$ is the torque, and $\Omega$ is the angular velocity. For the one-phase-on condition, (11) can be simplified as:

$$
T_{c}=\frac{1}{2} i_{a}^{2} \frac{d L_{a}}{d \theta}+i_{a} \frac{d \psi_{m a}}{d \theta}=T_{r}+T_{p m}
$$

where $T_{r}$ is the reluctance torque due to the variation of the inductance and $T_{p m}$ is the reaction torque due to the interaction between PM flux linkage and winding current.

When a two-stroke rectangular current, as shown in Fig. 9, is applied to the phase winding, the static torque and its components are shown in Fig. 10. The asymmetrical waveform of $T_{r}$ in two strokes is due to the inductances corresponding to different saturations, "PM $+3 \mathrm{~A}$ " in the first stroke and "PM-3A" in the second, leading to the nonzero average value of reluctance torque. Fig. 11 illustrates the static torque at different currents.

The torque can also be calculated by using the flux-current diagram technique [4]. Based on the FEA, the perphase flux-current diagram of the DSPM motor is illustrated in

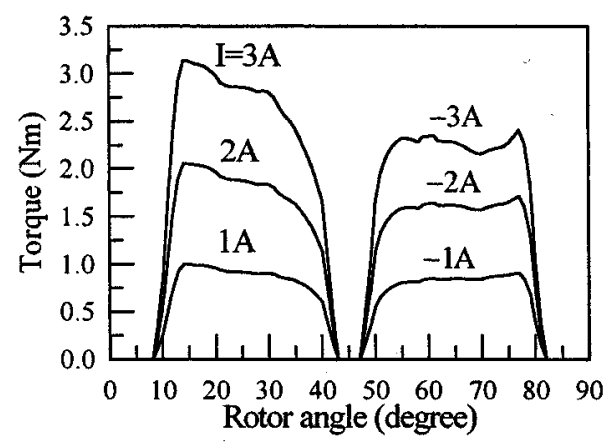

Fig. 11. Torque at different current.

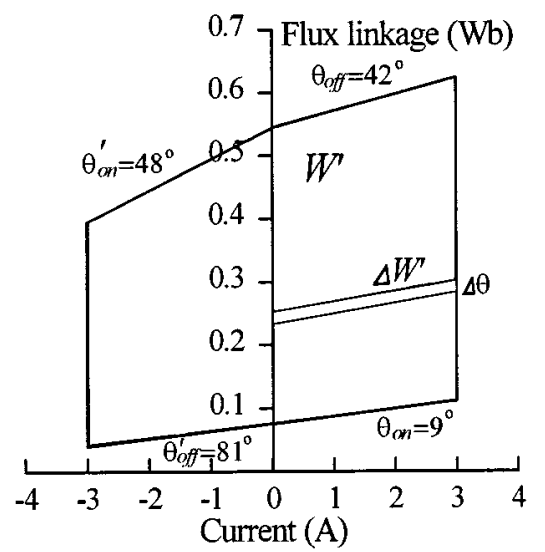

Fig. 12. Flux-current diagram of DSPM motor.

Fig. 12. By using the co-energy method, the torque is expressed as:

$$
T_{e}=\left.\frac{\partial W^{\prime}(i, \theta)}{\partial \theta}\right|_{i=\mathrm{constant}} \approx \frac{\Delta W^{\prime}(i, \theta)}{\Delta \theta}
$$

where $\Delta W^{\prime}$ is the increment of the co-energy and $\Delta \theta$ is the increment of the rotor position as shown in Fig. 12. The average torque in one conducting cycle is written as:

$$
T_{a v}=W^{\prime} / \theta_{c r}=W^{\prime} /\left(2 \pi / p_{r}\right)
$$

where

$W^{\prime} \quad$ is the co-energy equal to the area sur$\theta_{c r}=2 \pi / p_{r} \quad$ is the conducting cycle,

$p_{r} \quad$ is the number of rotor pole.

It is quite evident that the flux-current diagram method is more simple in calculating the average torque because only the flux linkages at four rotor positions, namely $\theta_{\text {on }}, \theta_{\text {off }}, \theta_{\text {on }}^{\prime}$ and $\theta_{\text {off }}^{\prime}$, are required. However, this method can only give the total static torque, but not the torque components.

\section{INDUCTANCE MEASUREMENT}

The inductance characteristics of the DSPM motor are functions of not only the rotor position but also the phase current. The available methods for measuring the inductance of conventional electric machines, such as induction machines and synchronous machines, are not valid for the DSPM motor. The 


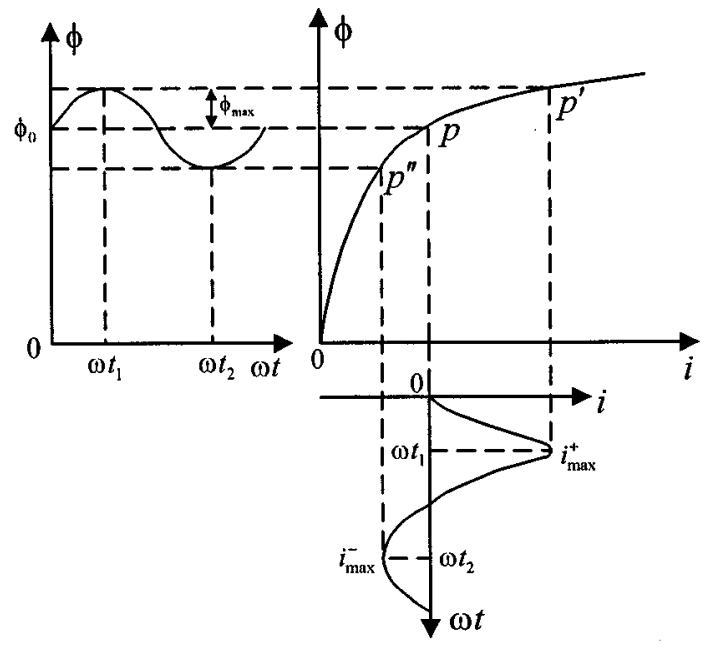

Fig. 13. Current waveform under sinusoidal flux.

inductance of the DSPM motor can only be measured at the static state and point by point. Moreover, it is almost impossible to eliminate the effect of the PM field on the magnetic saturation and hence the inductance once the motor is made. Therefore, new methods for measuring the inductance of DSPM motors are indispensable.

\section{A. Peak Value Method}

As shown in Fig. 13, $p$ is the operating point at no-load. As a sinusoidal voltage is applied to a phase winding, a sinusoidal component of flux is added to $\phi_{0}$. The operating point will move between $p^{\prime}$ and $p^{\prime \prime}$. The peak values of voltage and flux have following relationship:

$$
U_{m} \approx E_{m}=\omega w \phi_{\max }
$$

where

$$
\begin{array}{ll}
w & \text { is the number of turns in series per phase, } \\
\omega & \text { is the angular frequency of power supply, } \\
U_{m} \text { and } E_{m} & \begin{array}{l}
\text { are the peak values of voltage and EMF } \\
\text { respectively. }
\end{array}
\end{array}
$$

When the peak values of voltage and current are measured, the inductances can be expressed as:

$$
\begin{aligned}
& L^{+}=w \phi_{\max } / i_{\max }^{+}=U_{m} /\left(\omega i_{\max }^{+}\right) \\
& L^{-}=w \phi_{\max } / i_{\max }^{-}=U_{m}^{-} /\left(\omega i_{\max }^{-}\right)
\end{aligned}
$$

where $L^{+}$is the inductance when the armature field strengthens the PM field, and $L^{-}$is the inductance when the armature field weakens the PM field. Fig. 14 shows the current waveform recorded in the inductance measurement. As seen from Figs. 13 and $14, i_{\max }^{+}>i_{\max }^{-}$, so $L^{+}<L^{-}$.

In practice, however, the voltage $U$ across the inductance is unmeasurable due to the resistance of the phase winding. It can only be calculated based on the measured supply voltage $U_{s}$, input current $I$ and input power $P$. Alternatively, based on the power factor angle $\varphi, U_{m}$ can be deduced as follows:

$$
\begin{aligned}
\dot{U}_{s m} & =U_{s m} \angle 0^{\circ} \\
\dot{I}_{\max } & =I_{\max } \angle \varphi \\
\dot{U}_{m} & =\dot{U}_{s m}-\dot{I}_{\max } R
\end{aligned}
$$

where $U_{s m}$ is the peak value of the $U_{s}$ as shown in Fig. 15 .

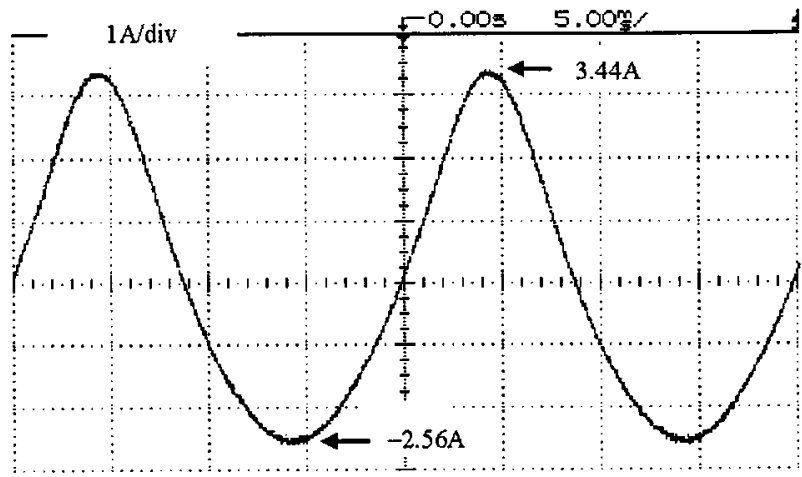

Fig. 14. Current waveform recorded in inductance measurement.

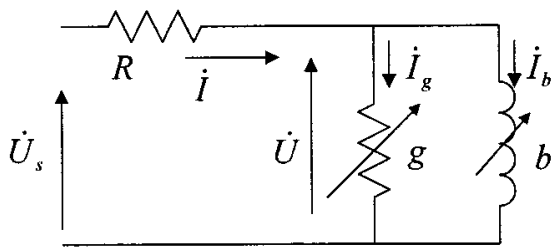

Fig. 15. Equivalent circuit of phase winding.

\section{B. RMS Value Method}

If the RMS values of voltage and current as well as the input power are measured, the average value of selfinductance can be approximately obtained as:

$$
L=\frac{1}{\omega} \frac{b}{g^{2}+b^{2}}
$$

where

$$
\begin{array}{ll}
g & =I_{g} / U, \\
b & =I_{b} / U,
\end{array}
$$

$I_{g}$ and $I_{b} \quad$ are the real and imaginary components of the current, respectively, as shown in Fig. 15.

Inductance $L$ in (21) can be considered as the average value of $L^{+}$and $L^{-}$approximately. When the phase current increases, the strengthening action to the PM field in the positive half-cycle leads to higher magnetic saturation and hence $L^{+}$will decrease, while the weakening action to the PM field leads to lower magnetic saturation and hence $L^{-}$will increase. However, the increment of $L^{-}$will be larger than the decrement of $L^{+}$due to the nonlinear magnetizing characteristics of the ferromagnetic material. This well explains the phenomenon found in the experiment that the higher the voltage supplied to the phase winding, the larger the value of self-inductance obtained by the RMS value method. Similarly, this approach can be applied to the mutual inductance measurement.

Table I shows a comparison of the calculated and measured self-inductances at two typical rotor positions for $i=2.5 \mathrm{~A}$. Also, Table II lists a comparison of the mutual inductances $L_{a b}$ at three typical rotor positions for $i=1.4 \mathrm{~A}$. As expected, good agreements are found.

\section{CONCLUSION}

The magnetic field of a new DSPM motor is analyzed by using 2D FEM, showing that the magnetic flux is mainly 
TABLE I

SELF-INDUCTANCES

\begin{tabular}{l|l|l|l|l}
\hline $\begin{array}{c}\theta \\
\left({ }^{\circ}\right)\end{array}$ & $\begin{array}{l}L^{+} \\
(\mathrm{mH})\end{array}$ & $\begin{array}{l}L^{-} \\
(\mathrm{mH})\end{array}$ & $\begin{array}{l}\text { Calculated } \\
(\mathrm{mH})\end{array}$ & $\begin{array}{l}\text { Measured } \\
(\mathrm{mH})\end{array}$ \\
\hline 15 & 18.24 & 20.49 & 19.37 & 20.5 \\
45 & 26.83 & 47.14 & 36.99 & 39.8 \\
\hline
\end{tabular}

TABLE II

MUTUAL INDUCTANCES $L_{a b}$

\begin{tabular}{|c|c|c|c|c|}
\hline \multirow{2}{*}{$\theta\left({ }^{\circ}\right)$} & \multicolumn{3}{|c|}{ Calculated } & \multirow{2}{*}{$\begin{array}{c}\text { Measured } \\
(\mathrm{mH})\end{array}$} \\
\hline & $L_{a b}^{+}(\mathrm{mH})$ & $L_{a b}^{-}(\mathrm{mH})$ & $L_{a b}(\mathrm{mH})$ & \\
\hline 15 & -6.60 & -6.28 & -6.44 & -6.65 \\
\hline 45 & -5.70 & -8.02 & -6.86 & -6.76 \\
\hline 75 & -2.24 & -2.47 & -2.36 & -2.8 \\
\hline
\end{tabular}

contributed by PMs, while the armature field contributes little to the magnetic flux but changes the distribution of the field. Based on the FEA, the static characteristics of DSPM motor, namely PM flux linkage, self-inductance, mutual inductances, and static torque, are deduced, in which the effect of cross-coupling between the PM flux and armature flux on inductances is firstly taken into account. The results indicate that the effect of the cross-coupling and the mutual inductance in the DSPM motor are significant and nonnegligible. Both the inductance-flux method and the flux-current diagram method are applied to the torque calculation, showing that the former can give clear physical insight to torque components, while the latter is easier for the average torque calculation. The method for measuring the inductance of the DSPM motor is investigated. Two new methods, namely peak value method and RMS value method, are proposed and implemented. The experimental results verify the proposed theoretical analysis.

\section{REFERENCES}

[1] S. Huang, J. Luo, F. Leonardi, and T. A. Lipo, "A general approach to sizing and power density equations for comparison of electrical machines,"IEEE Trans. Industry Application, vol. 34, no. 1, pp. 92-97, Jan. 1998.
[2] Y. Liao, F. Liang, and T. A. Lipo, "A novel permanent magnet motor with doubly salient structure," IEEE Trans. Industry Applications, vol. 31, no. 5, pp. 1069-1078, Sept. 1995.

[3] M. Cheng, K. T. Chau, and C. C. Chan, "A new doubly salient permanent magnet motor," in Proceedings of the 2nd IEEE International Conference on Power Electronics Drives and Energy Systems for Industrial Growth, 1998, pp. 2-7.

[4] D. A. Staton, R. P. Deodhar, W. L. Soong, and T. J. E. Miller, "Torque prediction using the flux-MMF diagram in $\mathrm{AC}, \mathrm{DC}$, and reluctance motors," IEEE Trans. Industrial applications, vol. 32, no. 1, pp. 180-188, Jan. 1996.

Ming Cheng was born in Jiangsu, China. He received the B.Sc. (Eng.) and M.Sc. (Eng.) degrees in electrical engineering in 1982 and 1987, respectively, from Southeast University, Nanjing, China. He is currently working toward the $\mathrm{Ph} . \mathrm{D}$. degree at the University of Hong Kong. Prior to entering the Ph.D. program, he was an Associate Professor with the Department of Electrical Engineering, Southeast University. His areas of interests include electrical machine and drive design, modeling, simulation, and power electronics. He has published some 20 papers in this area. He is the recipient or corecipient of several Chinese patents. He received the Second Prize of the Advancement of Science and Technology from National Education Commission of China in 1995.

K. T. Chan (M'89) received his first class honors B.Sc. (Eng.), M.Phil. and $\mathrm{Ph} . \mathrm{D}$. degrees in electrical and electronic engineering from the University of Hong Kong. Currently, he works as Associate Professor in the Alma Mater. Dr. Chau's teaching and research interests focus on three main areas-power converters, machines and drives, and electric vehicles. In these areas, he has published over a hundred refereed technical papers and some industrial reports. He has also served as chairs and organizing committee members for many international conferences.

C. C. Chan (M'77-SM'77-F'92) started his professional electrical engineering career in 1959 . He worked 11 years in industry and 26 years in academic institutions. He is now the Department Head and the Honda Chair Professor of Engineering of the Department and the Director of the International Research Centre for Electric Vehicles. He is very active in professional society activities. $\mathrm{He}$ is the Senior Vice President of the Hong Kong Institution of Engineers and holding over 20 posts in international committees. He also serves as Consultant to several organizations in Hong Kong and the U.S.A. He was awarded the Honorary Degree of Science and elected to be an IEEE Fellow for his contributions to the advancement of electric drives and electric vehicles. He is also a Fellow of IEE, HKIE and Hong Kong Academy of Engineering. 